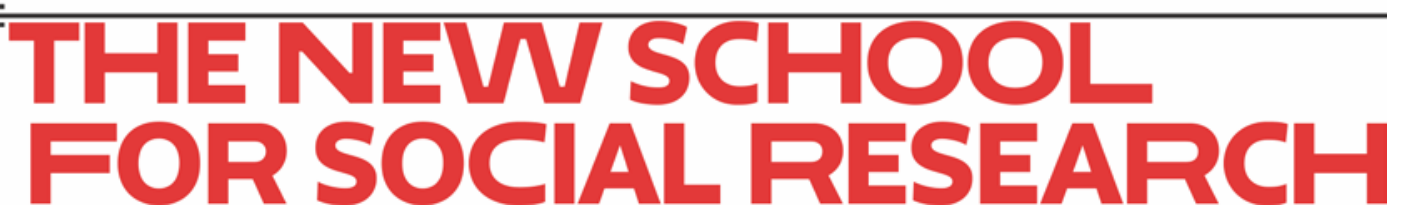

Mark Setterfield

\title{
Whatever happened to the 'Goodwin pattern'? Profit squeeze dynamics in the modern American labour market
}

January 2021

Working Paper 01/2021

Department of Economics

The New School for Social Research 


\title{
Whatever happened to the 'Goodwin pattern'? Profit squeeze dynamics in the modern American labour market
}

\author{
Mark Setterfield* \\ January 14, 2021; revised April 15, 2021
}

\begin{abstract}
The 'Goodwin pattern' - an anti-clockwise rotation in real activity $\times$ wage share space recurring at intervals that correspond roughly to the duration of business cycles - is an enduring feature of high-frequency dynamics in capitalist economies. It is well known that the centre or focus of this rotation shifts over time. More recently, however, the Goodwin pattern seems to have broken down, the wage share no longer increasing as the real economy improves over the course of short-term booms. In this paper, the apparent breakdown of the Goodwin pattern is associated with the consolidation of an 'incomes policy based on fear' that is part-and-parcel of neoliberalism. As a result of this incomes policy based on fear, the institutional structure of the labour market disciplines labour at any rate of unemployment. This decouples wage-share dynamics from the state of the real economy, with the result that as recently witnessed in the US, the wage share is rendered invariant to improvements in economic performance over the course of short-term cyclical booms.
\end{abstract}

JEL codes: E11, E12, E25, E64

Keywords: Goodwin pattern, distributional conflict, worker insecurity, incomes policy based on fear

\section{Introduction}

According to a substantial empirical literature, capitalist economies are characterized by short-cycles that involve a common empirical signature: the 'Goodwin pattern'. The Good-

\footnotetext{
*Professor of Economics, New School for Social Research; email mark.setterfield@newschool.edu.
} 
win pattern describes an anti-clockwise rotation in real activity $\times$ wage share space, recurring at intervals that roughly correspond to business cycle frequency. Numerous explanations have been forwarded for this key stylized fact of high-frequency capitalist macrodynamics $1^{1}$ More recently, however, attention has focused on the possibility that the Goodwin pattern has broken down. While the centre or focus of the Goodwin pattern has long been understood to shift between discrete historical periods, discussion of an apparent breakdown of the Goodwin pattern is an altogether more contemporary phenomenon.

The purpose of this paper is to document and furnish a theory of the apparent recent breakdown of the Goodwin pattern. Central to the theory advanced is the notion that contemporary neoliberal capitalism is based on an 'incomes policy based on fear' (Cornwall, 1990) that substitutes institutionalized worker insecurity for the 'threat of the sack' and, in so doing, loosens the connection between variations in the rate of employment, wage bargaining, and the behaviour of the wage share. The remainder of the paper is devoted to the empirical basis for and development of this theory, and is organized as follows. Section 2 explores the evidence that has established the Goodwin pattern as a prominent stylized fact in advanced capitalist economies. Section 3 examines the evidence that this pattern has recently broken down. Section 4 provides an explanation for the breakdown of the Goodwin pattern in terms of the consolidation of an incomes policy based on fear arising from the institutional structure of the labour market in neoliberal capitalism. Finally, section 5 concludes.

\footnotetext{
${ }^{1}$ The progenitor of these analyses is Goodwin (1967), but see also the qualitatively different models of Skott (1989); Barbosa-Filho and Taylor (2006); and Stockhammer and Michell (2016). For recent surveys of this literature, see Blecker and Setterfield (2019) and Flaschel et al. (2020).
} 


\section{An enduring stylized fact}

\subsection{What is the 'Goodwin pattern'?}

The 'Goodwin pattern' is named for the famous Marxian model of cyclical growth developed by Goodwin (1967). It can be regarded as a basic stylized fact of advanced capitalist economies, describing a cyclical pattern of high-frequency co-movements between measures of real economic activity on one hand, and measures of the distribution of income on the other. Specifically, the Goodwin pattern is associated with either clockwise rotations in wage share $\times$ real performance space, or alternatively (and equivalently) counter-clockwise rotations in real performance $\times$ wage share space $2^{2}$ In other words - and without imputing any causeeffect relationships between the variables involved - as real economic performance improves, the wage share is observed to first fall then rise, and when real performance subsequently deteriorates, the wage share first continues to rise before subsequently falling back.

It is generally accepted that the centre or focus of the rotation characteristic of the Goodwin pattern can shift, and that such shifts are evident in the historical record. In what follows, we treat this observation as being indicative of structural modifications to the basic workings of capitalism - in this case, the nature and outcomes associated with distributional conflict - that are brought about by the transition between different long-run phases of growth. Two particular phases of growth will be of paramount importance in what follows: the post-war Golden Age (1948-73) and the more recent Neoliberal Boom (19902007). By conceiving the Goodwin pattern as a high-frequency phenomenon occurring within low frequency phases of growth, our interpretation of this statistical regularity is similar to that of Mohun and Veneziani (2008), who see it as characteristic of shorter cycles taking place in the midst of longer-term trends associated with structural change in capitalist economies.

\footnotetext{
${ }^{2}$ As will become clear below, observation of the Goodwin pattern is robust to changes in the precise measure of real economic performance.
} 


\subsection{Empirical evidence}

Figure 1 provides evidence of the Goodwin pattern in the US economy from 1948-2019. Figure 1 is drawn in wage share $\times$ real performance space (with the wage share on the abscissa and the employment rate on the ordinate), depicting clockwise rotations over time. Three different complete business cycles are drawn to attention $3^{3}$ one of which (1960-69) is representative of Golden Age experience, the other two (1990-2000, 2000-2007) making up the Neoliberal Boom 4 Two observations are merited based on the data presented in figure 1 . First, there are extremes of unemployment (i.e., markedly lower than average employment rates) in 1975, 1982 and 2010, resulting from crises (1973-74, 1979-81, and 2007-09) that can be associated with the termination of phases of growth in the US economy (the Golden Age and the Neoliberal Boom, respectively). Second, apart from the fact that the patterns traced out over the course of each cycle are generally consistent with the clockwise rotation (in wage share $\times$ real performance space) typical of the Goodwin pattern, it is notable that the rotation from 1960-67 is further to the right in figure 1 than that during either 1990-2000 or 2001-2007. This is consistent with the observation made previously, that the centre or focus of the Goodwin pattern shifts over time, being centred on different point values of the wage share and employment rate during different historical periods. These periods, in turn, correspond to longer-term structural changes associated with the transition between different phases of growth - in this case, the Golden Age and the Neoliberal Boom. Specifically, the leftward shift of the centre or focus of the Goodwin pattern is consistent with the deterioration of the wage share under neoliberalism as compared with the mid-twentieth century Golden Age. Moreover, the fluctuations in the employment rate associated with the Goodwin pattern after the 1960s are (as can be seen from figure 1) orders of magnitude

\footnotetext{
${ }^{3}$ The dating of these business cycles is based on National Bureau of Economic Research (NBER) business cycle dating - see www2.nber.org/cycles.

${ }^{4}$ Notice that figure 1 also draws attention to US experience since the 2007-2009 financial crisis and Great Recession. We will return to discuss this experience in section 3.
} 


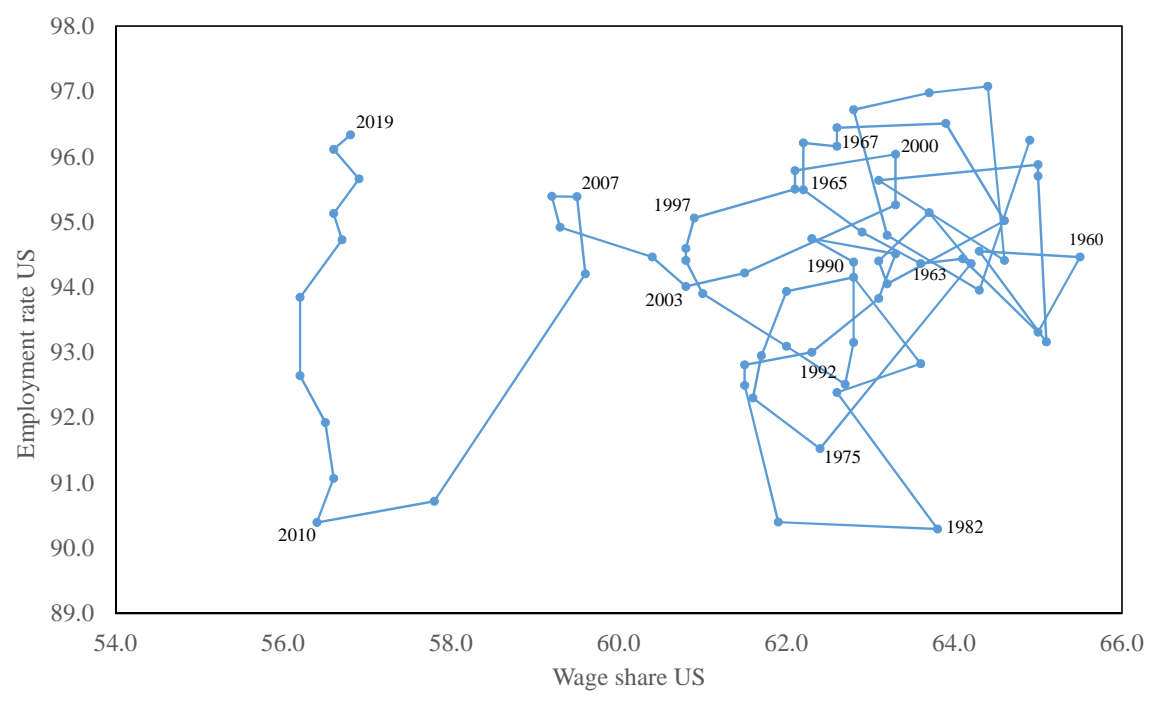

Figure 1: The distributive cycle: US 1948-2019

larger than those observed in the data prior to the 1970s. This development is suggestive of a greater willingness to sacrifice employment in order to discipline labour and so control the wage share - what Balogh (1982), in his assessment of similar developments in the UK, termed the 'incomes policy of Karl Marx' (see also Setterfield (2006)).

Descriptive analyses of the data similar to that above, and providing evidence confirmatory of the existence of the Goodwin pattern in advanced capitalist economies, are widespread. For example, Flaschel and Groh (1995) and Harvie (2000) observe the Goodwin pattern over periods of 10-15 years in the data for samples of 8 and 10 OECD countries, respectively. Patterns in US macroeconomic data similar to those observed in figure 1 have been brought to attention previously by various authors. Using a data set similar to that on which figure 1 is based for the period 1948-2008, Zipperer and Skott (2011, pp.35-6) remark on the shift in the centre or focus of the Goodwin pattern in the US economy, first towards lower rates of employment in the 1970s and 1980s, and then towards higher rates of employment and lower values of the wage share thereafter. Barbosa-Filho and Taylor (2006, pp.389-91), meanwhile, focus on the relationship between the rate of capacity utilization 
(rather than the employment rate) and the wage share of income in the US economy from 1929-2002 Despite changing the measure of real economic performance and examining a longer period of time, the authors once again observe the same clockwise rotations in the data that are observed in figure 1, and also draw attention to similar shifts in the centre or focus of this pattern..$^{6}$ The only exception they note is during the period 1944-50, when the pattern of rotation runs contrary to that associated with the Goodwin pattern, but this they explain in terms of simultaneous declines in the wage share and the rate of capacity utilization from their wartime peaks.

Aside from the descriptive statistics illustrated and discussed above, there are various other sources of evidence suggesting that the Goodwin pattern is representative of higherfrequency cycles in advanced capitalist economies.7 For example, Barrales-Ruiz and von Arnim (2017) use wavelet decomposition methodology to study cycles of different periods in US data since 1948. The authors find a consistent Goodwin pattern for cycles of 4 to 8 and 8 to 16 years in length, regardless of the measure of real economic activity used (the output gap, income-capital ratio, or employment rate). Building on this approach, and using a variety of different measures of both real activity and the wage share, Barrales-Ruiz et al. (2020) first show that when considered individually, all activity and wage share measures display similar high-frequency dynamics. Their wavelet analysis then confirms this dynamical coherence, and an analysis of leads and lags reveals that real activity leads the wage share at high frequencies, consistent with the Goodwin pattern.

Meanwhile, McAdam et al. (2019) study data spanning more than a century for three advanced capitalist economies: the US (1898-2010), the UK (1856-2010) and France (1896-

\footnotetext{
${ }^{5}$ Note that for the purpose of demonstrating the relationship between real activity and income distribution characteristic of the Goodwin pattern, the capacity utilization rate can be regarded as a plausible substitute for the employment rate. While the capacity utilization rate and employment rate are correlated, however, the relationship between the two variables need not be straightforward (Skott, 2017).

6 Barbosa-Filho and Taylor (2006) in fact report counterclockwise rotations in the data, but this is simply because it is presented in real performance $\times$ wage share space.

${ }^{7}$ For a more extensive review of this literature, see Barrales-Ruiz et al. (2020).
} 
2010). They find that at high frequencies (2-4 and $4-8$ years), the wage share has a negative impact on output growth. Elsewhere, using US wage share and employment rate data 1948-2016, Araujo et al. (2019) study the impulse-response functions of an estimated VAR model. They find that the wage share responds to shocks to the employment rate and the employment rate responds to shocks to the wage share in a manner consistent with the Goodwin pattern. The duration of these responses depends on the way in which the employment rate and wage share data is filtered, but in all cases the effects of the shock disappear within 3 to 5 years 8 Similar results using VARs in various different measures of real performance and the wage share for US data 1949-2020 are reported in Barrales-Ruiz et al. (2020), although the authors report that whereas shocks to the wage share have effects on real performance that dissipate within 4 years, shocks to real performance have effects on the wage share that persist for more than 6 years. Finally, based on US data 1973-2018 and VARs in the wage share, capacity utilization rate, and real exchange rate, Basu and Gautham (2020) again produce impulse response functions consistent with the Goodwin pattern. The authors do not comment directly on the duration of the effects of shocks to the wage share on real performance (and vice versa), but their results are broadly consistent with those of Barrales-Ruiz et al. (2020): real activity adjusts faster (within 1-2 years) than distribution, which still shows persistent effects of a shock to real activity after 4 years.

Based on the stylized facts presented in their own earlier work (Zipperer and Skott, 2011), Skott and Zipperer (2012, pp.293-4) conclude that there is strong evidence of counterclockwise movements in real activity $\times$ wage share space for the US economy (and somewhat weaker evidence of the same pattern in other advanced capitalist economies) at roughly busi-

\footnotetext{
$\sqrt[8]{\text { Araujo et al. }}(2019)$ discover that their results are sensitive to the choice of real performance variable, the effects of the wage share on real performance disappearing when the capacity utilization rate is substituted for the employment rate. They suggest that the goods market and labour market should not be considered equivalent, which leads them to a reformulation of Goodwin-type dynamics based on a three-way interaction between the goods market, labour market, and wage share. A similar reformulation can be found in Skott (1989, 2010), which contribution is discussed briefly below.
} 
ness cycle frequency, that is robust to changes in the precise definition and measurement of variables 99 These same conclusions appear consistent with the variety of evidence reviewed above. That having been said - and perhaps inevitably, given the nature of empirical macroeconomics - the seeming ubiquity of the Goodwin pattern is not without qualifications and caveats. First, the Goodwin pattern is not evident in lower frequency cycles of the sort associated with the rise, decline and rise of the consecutive phases of growth. Hence McAdam et al. (2019) find that the wage share leads growth positively at frequencies of 32 years and above in the US, UK, and France, which observation is inconsistent with the countercyclical rotation in real activity $\times$ wage share space characteristic of the Goodwin pattern. Set against this, those who consider the Goodwin pattern to be characteristic of real-world capitalism seldom (if ever) claim that the pattern can be found in low-frequency data.

Second, and perhaps more importantly, Cauvel (2018) argues that pro-cyclical variation in the wage share of income is largely caused by pro-cyclical variation in labour productivity (due to labour hoarding during recessions), rather than variations in the real wage (see also Lavoie (2017); Hartley (2019)).10 This claim strikes at the very mechanism - associated with the notion that tightening the real economy diminishes the profit share by disadvantaging capital in the process of distributional conflict with labour - that is central to most interpretations of the Goodwin pattern Goodwin, 1967; Barbosa-Filho and Taylor, 2006, Stockhammer and Michell, 2016). Note, however, that Cauvel's argument calls into question the source of the Goodwin pattern, rather than the existence of the pattern per se. Indeed, controversy about the causes of the Goodwin pattern is rife even within the literature that associates the pattern itself with variations in distributional conflict in the labour market. For

\footnotetext{
${ }_{9}$ Skott and Zipperer $(2012)$ actually refer to clockwise movements in real activity $\times$ profit share space, but this amounts to the same thing.

${ }^{10}$ Since $\nu=\frac{w N}{p y}=\frac{\omega}{q}$, where $\nu$ is the wage share, $w$ is the nominal wage, $N$ is the level of employment, $p$ is the general price level, $y$ is the level of real output, $\omega$ is the real wage, and $q$ is the level of labour productivity, changes in the wage share can result from changes in the real wage or changes in the level of labour productivity (or both).
} 
example, Stockhammer and Michell (2016) view distributional conflict as a residual accompaniment of a cyclical mechanism based on real-financial interactions, rather than as being a causal driver of co-movements in real activity and factor shares - which is the interpretation in Goodwin (1967) and Barbosa-Filho and Taylor (2006) (approaches that otherwise differ with respect to their focus on supply-led and demand-led real-sector dynamics, respectively). These differences of opinion demonstrate that the 'profit squeeze' inherent in the Goodwin pattern, whereby a tighter labour market is associated with a higher wage share, need not be indicative of an economy that is 'profit-led' 11 They also demonstrate that even as acceptance of the Goodwin pattern is widespread among macroeconomists, it remains - like most other purported empirical regularities in the field - a source of controversy.

\section{Goodbye, old friend?}

We have already noted the propensity for the centre or focus of the Goodwin pattern to shift between different longer-term phases of growth. It is also possible that structural characteristics of different phases of growth result in modifications of the basic pattern itself, and that this is precisely what has been observed in US data since 2000. Hence one of the most important controversies concerning the Goodwin pattern is the claim that it has recently broken down. According to this view, even if the Goodwin pattern can be observed in the data over broad sweeps of previous history, it has weakened or even disappeared

\footnotetext{
${ }^{11}$ Indeed, the model of Stockhammer and Michell (2016) is explicitly wage-led.

Note also that as defined here, the 'profit squeeze' inherent in the Goodwin pattern is merely an association between a tighter labour market and a higher wage share: no causal connection between these phenomenon is pre-supposed, or need exist. Hence in the neo-Harrodian model of Skott (1989, 2010), there is no direct causal relationship between tightening of the labour market and the diminution of the profit share of the sort that exists in each of the models associated with Goodwin (1967), Barbosa-Filho and Taylor (2006), and Stockhammer and Michell (2016) (despite the aforementioned differences between these models with respect to the causal role of distributional conflict in the real dynamics of the system). In the Skott (1989, 2010) model, the behaviour of the profit share results from events in the goods market: there is no direct link between the state of the labour market, wage bargaining, and the size of the profit share. This model nevertheless produces outcomes consistent with the Goodwin pattern.
} 
altogether during the neoliberal era. Over the last two decades, US capitalism has ceased to be characterized by 'profit squeeze' dynamics, wherein tightening of the labour market over the course of short-term booms in economic activity is associated with a higher wage share of income.

Nikiforos (2017, pp.248-50), using US capacity utilization rate and wage share data over the period 2001-2013, draws attention to a fall in the wage share accompanying the rise in capacity utilization as the US economy recovered from the 2001 recession, a shift in the relationship between these variables during the Great Recession, and a further decline in the wage share as the economy began to recover (and capacity utilization rose) from 2009-2013, during the initial stages of recovery from the Great Recession. He notes, however, that the further decline in the wage share after 2009 is more modest than that observed during the previous business cycle boom, and it is clear from inspection of his figure 3 (Nikiforos, 2017. p.250) that most of this decline occurs in 2009-2010, the wage share essentially stabilizing thereafter even as capacity utilization continues to rise.

Figure 2 focuses on the relationship between the wage share and the employment rate in the US since 2000, in an effort to both update and reinforce Nikiforos's observations. It is clear that during the expansion following the 'dot com' recession in the US in 2000 (leading up to the onset of the Great Recession in 2007), there was no systematic profit squeeze: even as the US employment rate recovered markedly after 2003, the wage share fell through 2006. It rose only very belatedly (and modestly) during the final year of this boom, from 2006-07. Figure 2 also shows that while the onset of the Great Recession produced outcomes more consistent with the Goodwin pattern, both the employment rate and the wage share falling substantially from 2007 through 2010, there was (once again) no profit squeeze during the ensuing recovery. The wage share declined markedly during the first official year of economic expansion (2009-2010). Thereafter, and even as the employment rate rose by fully six percentage points between 2010 and 2019 so that the economy reached 
rates of unemployment (below 4\%) last seen in the early 1970s, the wage share remained essentially constant.

Figure 2: The wage share - employment relationship in the US, 2000-2019

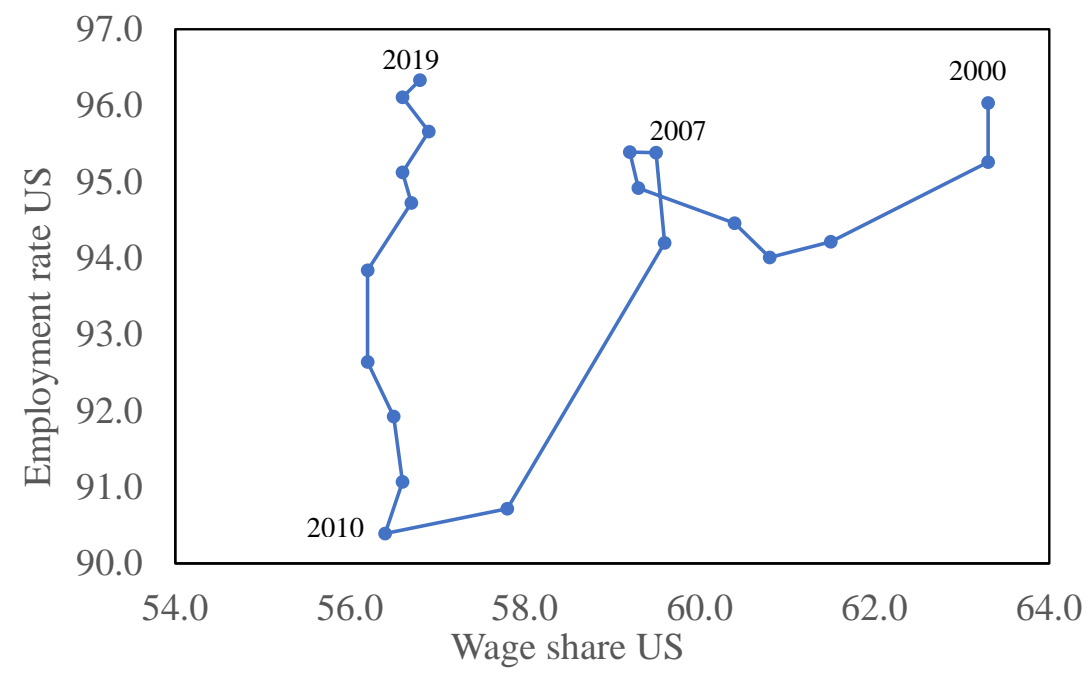

Before we conclude that the Goodwin pattern has disappeared, however, the descriptive statistics outlined above merit some qualification. First, it would be wrong to suggest that it is only during the past two decades that data at odds with the Goodwin pattern have been observed. For example, Desai (1984) shows that in UK data from 1855-1965, long periods during which the Goodwin pattern is evident are interspersed with periods of political and/or economic upheaval (such as the interwar years) when the pattern disappears ${ }^{12}$ Second, there is the question of who receives wage income and hence the changing composition of "wage earners'. It is well known that recent increases in income inequality are, to a substantial extent, associated with increases in wage inequality. Mohun (2006) argues that the highest 'wage' incomes associated with this phenomenon (salaries paid to CEOs, for example) are

\footnotetext{
${ }^{12}$ This observation, in turn, draws attention to potential interaction between secular/structural developments and shorter-term cyclical forces, and the influence of this interaction on the relationship between real activity and the wage share in raw data. We will discuss this further below, under the rubric of trend-cycle interaction in real performance and wage share data.
} 
conceptually part of the profit share of income. Hence the growing share of these 'wage earners' may affect contemporary interpretation of the relationship between real activity and the wage share as conventionally defined. Third, there is the question as to whether the raw data plotted in figure 2 (and discussed by authors such as Nikiforos, 2017), and that reflect both trend and cyclical developments, adequately reflect the short-cycle dynamics that lie behind the Goodwin pattern ${ }^{13}$ It is possible, for example, that forces associated with the long-term trend decline in the wage share noted previously in this paper countervailed shorter-term cyclical forces during recent cyclical booms, thwarting observation of (but not providing evidence of a breakdown in) the Goodwin pattern in recent data.

Looking beyond descriptive statistics, it was noted earlier that a number of studies using wavelet decomposition and/or VAR analyses find evidence consistent with the Goodwin pattern in the US. But some of these studies have begun to point to changes in the relationship between real activity and distribution in recent data. For example, and as previously reported, Barrales-Ruiz and von Arnim (2017) find robust evidence consistent with the Goodwin pattern at frequencies less than 16 years based on wavelet decompositions. But the authors note that since 1980, something has changed at lower frequencies. Prior to 1980, a complete anti-clockwise rotation is evident in real activity $\times$ wage share space between 1955 and 1980. But post-1980, there is an initial improvement in real activity with little or no accompanying rise in the wage share - following which both variables decline sharply from the late 1990s onwards. They also note that evidence is suggestive of a single Goodwin 'super cycle' from 1950-2000, but regardless of the their measure of real activity, this orbit is not completed thereafter. Instead, real activity and the wage share once again collapse in tandem.

Of course, we have already established that the prevailing consensus about the ubiquity of

\footnotetext{
${ }^{13}$ Of course, this has not prevented appeal to such data in the past, in some of the literature mentioned previously that purports to identify the ubiquity of the Goodwin pattern in advanced capitalist economies.
} 
the Goodwin pattern is that it is a high frequency phenomenon. But even at high frequencies, evidence is emerging that change may be afoot. Mendieta-Muñoz et al. (2020) explore the sensitivity of the wage share to various shocks (including shocks to aggregate demand and hence real output) using US data that is partitioned into two sub-samples: an immediate post-war era (1948-1984) and a neoliberal era (1985-2018). They present evidence of a statistically significant structural break in the data justifying this partition. They then demonstrate a weakening of the profit squeeze mechanism, both absolutely and relatively, during the neoliberal era (as compared to the immediate post-war era). The authors caution that the absolute decline in the profit squeeze mechanism is not statistically significant. But the mechanism has also declined relatively, becoming a less important driver of changes in the wage share than either wage shocks or productivity shocks. This leads the authors to conclude that wage shocks - which they associate with changes in structural features of the labour market rather than the state of the real economy - are now unequivocally the main driver of changes in the US wage share.

While it would be unwise to exaggerate the strength of the evidence just discussed, it nevertheless appears that regardless of how real performance is measured, twenty-first century American capitalism may no longer exhibit high-frequency profit squeeze dynamics to the extent that it once did. The raw data in figure 2 are unequivocal: the wage share having declined to post-war lows, improved real economic performance during short-term booms in economic activity is no longer accompanied by improvement in the wage share. Studies such as Mendieta-Muñoz et al. (2020), meanwhile, suggest a weakening of the profit squeeze mechanism during the neoliberal era, at least relative to other mechanisms that now dominate wage share dynamics. In short, an important part of the Goodwin pattern seems to have disappeared - or at least to be in the process of disappearing - from the data. If this provisional summary statement is accepted, the question then arises as to how this apparent breakdown in the Goodwin pattern during the neoliberal era can be explained? 


\subsection{A preliminary explanation: too much slack?}

It is well known that 'headline' employment/unemployment statistics now systematically understate the true extent of 'slack' in the US economy 14 This is because of changes since the mid-twentieth century Golden Age in both the nature of employment (fewer full-time, year round jobs as a proportion of total employment) and attachment to the labour force (the discouraged worker phenomenon, which has rendered labour force participation more pro-cyclical) ${ }^{15}$ In recognition of these changes, the Bureau of Labor Statistics (BLS) now reports multiple unemployment rates, including 'headline' unemployment (U3) $t^{16}$ and broader measures of unemployment such as U6 17 Figure 3 illustrates both of these measures of unemployment since the onset of the Neoliberal Boom. As is clear from figure 3, U6 was considerably higher than U3 throughout the 2009-2019 recovery, remaining as high as $7 \%$ even as the peak of the cycle was reached 18

A second alternative measure of labour market slack is unemployment intensity (Shaikh, 2016, p.662), which is calculated by multiplying the unemployment rate by a measure of the duration of unemployment spells. Since by definition $U=i d$, where $U$ is unemployment, $i$ is the incidence of unemployment, and $d$ is the average duration of an unemployment spell, the same unemployment rate can represent either a better-functioning (high incidence, low duration) or a worse-functioning (low incidence, high duration) labour market, in which

\footnotetext{
${ }^{14}$ See, for example, $($ Komlos, 2019$)$ and the references therein.

${ }^{15}$ As Perez-Arce and Prados (2021, p.619) note, contemporary evidence suggests that the discouraged worker effect dominates the counter-cyclical 'added worker effect' - whereby households add more members to the workforce in an effort to shore up household income during straitened economic conditions - rendering the labour force participation rate pro-cyclical on balance.

${ }^{16} \mathrm{U} 3$ measures the total number of unemployed persons as a percent of the civilian labor force.

${ }^{17} \mathrm{U} 6$ measures the total number of unemployed persons plus all persons marginally attached to the labor force plus the total number of persons employed part time for economic reasons, as a percent of the civilian labor force plus all persons marginally attached to the labor force.

${ }^{18} \mathrm{U} 6$ is not only higher that U3, but displays different short-term dynamics over the course of the business cycle, because involuntary part-time employment displays greater persistence than unemployment during recoveries (Komlos, 2019). This means not only that the gap between U6 and U3 varies over the cycle, but also that reliance on U3 underestimates the persistent labour market hardship during cyclical booms of particular sub-groups of the population - specifically, minority, younger, and less-well-educated workers, all of whom are more likely to experience involuntary part-time work (Komlos, 2019).
} 
Figure 3: Unemployment in the US Economy, 1991-2019

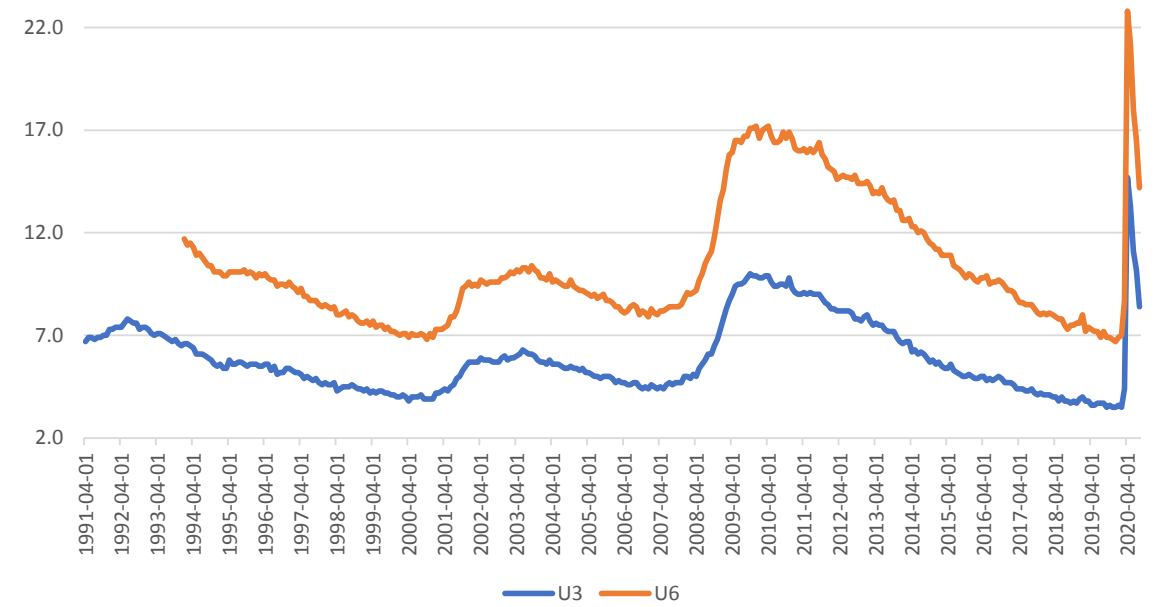

employed workers can exert either more or less pressure (respectively) on wages 19 As a measure of labour market slack, unemployment intensity $\left(U_{\text {int }}\right)$ corrects for this problem, since:

$$
U_{\text {int }}=U \cdot d=i d^{2}
$$

The same unemployment rate will now be associated with different values of $U_{\text {int }}$ in a low $i$, high $d$ labour market as opposed to a high $i$, low $d$ labour market. Specifically, we will observe a higher value of $U_{\text {int }}$ in the low $i$, high $d$ labour market, capturing the hidden slack in this labour market associated with its sclerosis. Figure 4 plots the value of unemployment

\footnotetext{
${ }^{19} \mathrm{~A}$ 'high incidence, low duration' labour market is better functioning in the sense that unemployment represents a brief transitional state between jobs, in the context of which its high incidence offers the prospect of better matches between workers and firms. It also means that workers have less to fear from any given rate of unemployment (their prospects of subsequent re-employment being good), enhancing their bargaining power and hence their influence on wages. A 'low incidence, high duration' labour market is worse functioning, meanwhile, in the sense that it is sclerotic: once entered, unemployment is a state from which it is difficult to escape, and flows between labour market states (and hence the potentially-productivity-enhancing movement of workers between jobs) is reduced. Fearing quasi-permanent unemployment, employed workers have more to fear from any given rate of unemployment, which will reduce their bargaining power and hence their influence on wages.
} 
intensity in the US economy since the onset of the Neoliberal Boom.

Figure 4: Unemployment Intensity in the US Economy, 1991-2019

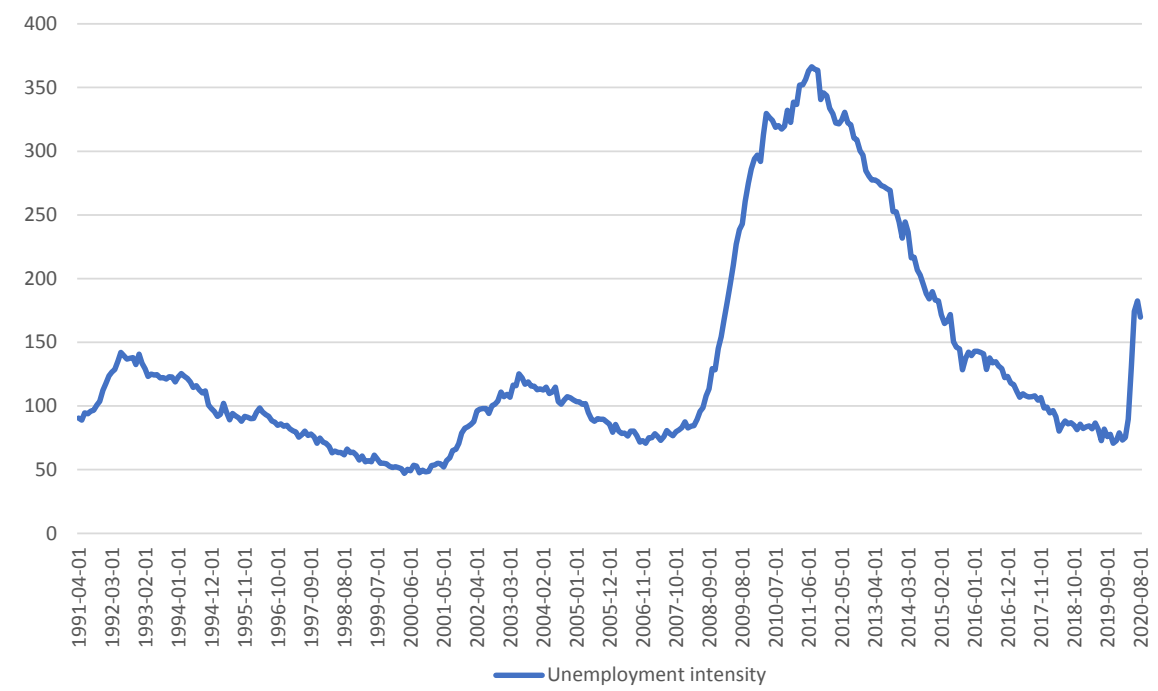

One possible explanation for the breakdown in the Goodwin pattern, then, might be that over the past two decades, there has always been too much slack in the labour market to put pressure on the profit share. The distinction between unemployment and unemployment intensity is important in this regard, because of the steady increase in the duration of unemployment in the US economy over the course of the post-war period - an increase that has been marked since the onset of the neoliberal growth episode. Hence the average duration of an unemployment spell in the US has risen from 9.2 weeks 1948-73, to 10.6 weeks 1974-89, to 16.3 weeks 1990-2019 20 Not surprisingly, then, there is a marked upward trend in unemployment intensity over the course of the post-war period (Paternesi Meloni and Stirati, 2020). Secular increases in labour market slack would therefore appear to help explain the long-term decline in the wage share evident in figure 1. Our concern is with high-frequency variations in the wage share, however - and inspection of figures 3 and 4 reveals that by any

\footnotetext{
${ }^{20}$ Authors calculations, based on FRED data (fred.stlouisfed.org/series/UEMPMEAN).
} 
measure, labour market slack varies over the course of the business cycle and fell markedly during the 2009-2019 recovery. On the face of it, then, there is still more or less slack in the US labour market over the course of the cycle, as a result of which there should be (in principle) correspondingly less or more pressure on the profit share. But as is evident from the contrast between the cyclical variation in unemployment and unemployment intensity in figures 3 and 4 , and the now-acyclical behaviour of the wage share in figure 2, measures of labour market slack continue to vary at high frequency in a manner that the wage share no longer does. The fact that the wage share has now essentially ceased to respond to even the substantial rise in the employment rate (6 percentage points) registered during the 2009-2019 recovery suggests that some other structural explanation of the events depicted in figure 2 is required.

\section{The disappearance of the Goodwin pattern: An ex- planation}

\subsection{The transition to neoliberalism}

According to its proponents, neoliberalism works by freeing the private sector from the fetters of the state and revitalizing the supply-side of the economy. In particular, the labor market is made 'flexible': disincentives to work (such as taxes and unemployment benefits) are lowered, and impediments to wage adjustment (such as trade unions and minimum wage legislation) attenuated or removed. The alleged result is a labour market that generates more jobs, resulting in higher output and so a healthier economy overall. Even the increased inequality associated with the initial changes to the structure of taxes and social benefits are allegedly offset by aggregate output gains that eventually ‘trickle down' to the less affluent.

Macroeconomic performance did, in fact, improve in the US after 1990, as compared to 
the previous two decades of inter regnum following the demise of the Golden Age. As the first two rows of table 1 make clear, the first full business cycle of the neoliberal era (1990-2000) re-established the low average rates of unemployment and inflation last seen towards the end of the post-war 'Golden Age' (represented by the period 1960-73 in the first column of table 11. This improvement in macroeconomic performance did not occur because of the effects of neoliberalism as envisaged by its progenitors, however. Instead, changes to the supply-side of the economy during the 1980s constituted a process of 'zapping labor' (Harrison and Bluestone, 1988). Post-1980 changes in public policy that claimed to make labor markets more flexible, together with various contemporaneous changes in corporate behavior, all succeeded in markedly increasing worker insecurity ${ }^{21}$ These changes included labor law 'reforms' that, among other things, made unionization by workers more difficult and de-unionization by firms easier (Block et al., 1996), resulting in a precipitous drop in the rate of unionization in the US, from a post-war peak of about $35 \%$, to $20 \%$ by the early 1980 s, to just $10 \%$ by 2019.22 Other changes included increases in 'non-standard' (i.e, part time and/or temporary) employment, that eroded the post-war norm of year-round, full-time work. This gave rise to under-employment in the form of 'involuntary' part-time/temporary employment, a counterpart to involuntary unemployment. The introduction of periodic 'downsizing' exercises by firms, meanwhile, created the credible threat of job loss independently of general economic

\footnotetext{
${ }^{21}$ It is important to note that the institutional changes that are the focus in what follows are not the only major structural change that has characterized the neoliberal era. Instead, all advanced capitalist economies have witnessed the continuation of longer-term trends towards deindustrialization and the rise of the service sector that have changed the composition of economic activity. This is important not only because deindustrialization contributes to deunionization (as will be argued below), but also because of its direct effect on wages and the rise of inequality. Hence the low productivity/(near) zero productivity growth that characterizes so-called 'stagnant' service sector industries (Baumol et al. 1989) means that not only are these industries labour-attracting (employment must grow rapidly as output in these industries grows because of the lack of productivity growth), they are also low wage/(near) zero wage growth industries, by virtue of their low productivity/(near) zero productivity growth. The direct contribution of deindustrialization to the growth of inequality will not be discussed further in what follows, but see, for example, Mendieta-Muñoz et al. (2020).

${ }^{22}$ The contemporary rate of unionization in the private sector is just $6 \%$, union representation being much greater in the public sector.
} 
conditions (Osterman, 1999). Worker insecurity was further enhanced by the emergence of a credible threat (on the part of firms) to relocate production between political jurisdictions. This threat of plant relocation began as a domestic phenomenon that witnessed the migration of industry within the US from traditional industrial areas in the north-east and mid-west to southern and south-western states. It then took on an international dimension thanks to the pro-corporate form taken by 'globalization', as encoded in various international trade agreements. The latter helped create an international institutional environment that makes little or no reference to labor standards, thus exposing US workers to competition from low-wage foreign workers - not only as a result of the greater internationalization of product markets, but also by enhancing the credibility of the threat of plant relocation. Together, these developments have transformed 'trade' from its mid-twentieth century form a process of competition between spatially-distinct and geographically immobile firms based on product and process innovations - into a competition between political jurisdictions to attract footloose corporations, on the basis of tax reductions and denuded environmental and labour standards 23

The combined effects of these various facets of the process of zapping labor are evident in the final row of table 1. This reports an index of worker insecurity based on numerical measures of the various phenomena described above. ${ }^{24}$ The index of worker insecurity rises precipitously during the 1980s and 1990s, as the institutional architecture of the neoliberal economy emerged.

The process of zapping labor described above made the neoliberal economy work by instituting an 'incomes policy based on fear' (Cornwall, 1990). In general, incomes policies are formal and/or informal institutions that frame and mediate aggregate wage and price

\footnotetext{
${ }^{23}$ This is what Palley (2019) calls 'barge economics', referring to former General Electric CEO Jack Welch's quip that, ideally, all physical plant would be located on barges that would continuously float between political jurisdictions to immediately take advantage of any cost advantage, regardless of its source.

${ }^{24}$ Details of the calculation of this insecurity index can be found in Setterfield (2005) and Setterfield and Lovejoy (2006).
} 
Table 1: US Macroeconomic Performance, 1960-2000

$1960-73 \quad 1974-79 \quad 1980-89 \quad 1990-2000$

\begin{tabular}{lcccc}
\hline \hline & & & & \\
Unemployment & 4.9 & 6.8 & 7.3 & 5.6 \\
Inflation & 3.1 & 9.6 & 5.6 & 3.1 \\
Wage share & 57.4 & 59.1 & 58.4 & 57.7 \\
Interest rate & 4.77 & 7.67 & 9.97 & 5.24 \\
Worker insecurity & $\mathrm{N} / \mathrm{A}$ & 0.21 & 0.57 & 0.82 \\
& & & & \\
\hline
\end{tabular}

Source: Setterfield 2006)

setting behaviour in a manner that reduces conflict over income shares. The archetypal incomes policy is based on cooperation and conciliation, ameliorating distributional conflict through consensus building. The neoliberal 'incomes policy based on fear' is, instead, a model of domination, in which conflict is ameliorated essentially by means of coercion - specifically, the imposition of capitalists' preferred distributional settlement on workers (Setterfield, 2006, 2007). First, workers were disempowered by the institutional changes outlined above. This reduced their ability to bargain for nominal wage increases, lessening their capacity to either seek improvements in their standard of living or even increase wages in the face of rising prices in order to protect their existing standard of living - an outcome that, ceteris paribus, lowers the real wage and hence the wage share of income 25 Since any increase in nominal wages results in an increase in the costs of production that may be passed on in the form of higher prices, the disempowering of workers under the incomes policy based on fear also reduced underlying inflationary pressures in the US economy. Not only could workers not initiate an inflationary process (by bargaining for higher nominal wages in the face of corporate

\footnotetext{
${ }^{25}$ In the presence of labour-saving technological change, any failure on the part of workers to bargain for real wage increases that keep pace with the rate of increase of productivity will have similar effect, lowering the wage share of income.
} 
resistance to increases in the real wage), neither could they propagate an inflationary process by merely seeking to defend their standards of living against price increases resulting from, for example, commodity price 'shocks' ${ }^{26}$ These developments are clearly seen in the second and third rows of table 1 where, following their rise during the 1970s, inflation and the wage share fell during the 1980s and 1990s.

By relieving pressure on inflation, the incomes policy based on fear simultaneously reduced the need for the Federal Reserve to perform this function themselves, by resort to restrictive monetary policy interventions designed to depress aggregate demand, raise unemployment, and discipline workers into moderating wage claims. The incomes policy based on fear made this policy response un-necessary: the very structure of the labor market created by the process of zapping labor now disciplined workers, by creating job and/or income insecurity at any rate of unemployment, eliminating the need for high unemployment to perform this disciplinary task ${ }^{27}$ This, in turn, freed the Federal Reserve to lower interest rates and allow unemployment to fall (and with it, incomes and hence profits to rise). Again, these developments are evident in table 1 (rows one and four), where marked declines in both interest rates and the rate of unemployment can be seen after 1990 .

In sum, the neoliberal restitution of Golden Age standards of macroeconomic performance evident in column five of table 1 (rows one, two, and four), where we see the return of a low inflation, low unemployment, and low interest rate economy in the US for the first time since the early 1970s, can be explained by the process of zapping labor evident in rows three and five of the same table, and its creation of an incomes policy based on fear. Taken together, these developments describe a process of 'balancing the macroeconomic

\footnotetext{
${ }^{26}$ The increases in the price of oil resulting from the US invasion of Iraq in 2003 and the impact of hurricane Katrina on oil refining capacity located on the Gulf of Mexico in 2005 are salient examples of this latter process during the period of the Neoliberal Boom.

${ }^{27}$ Even Alan Greenspan, the former Chair of the Federal Reserve, was explicit about this process, referring in Congressional testimony to the 'labor market fear factor' gripping American workers as a reason for diminished inflation concerns at the Federal Reserve.
} 
books on the backs of workers' (Setterfield, 2006), wherein the costs of achieving improved macroeconomic performance are borne uniquely by working households.

\subsection{The transition to neoliberalism and recent shifts in the centre or focus of the Goodwin pattern}

Central to the account provided above is the effective substitution of institutional conditions for unemployment as the key 'worker discipline device' moderating distributional conflict and hence the wage share of income (and the accompanying rate of price inflation). To see this in more detail, consider the following system of equations:

$$
\begin{gathered}
\hat{w}=\mu\left(v_{W}-v\right) \\
\hat{p}=\phi\left(v-v_{F}\right) \\
\mu=h(e, I), h_{e}>0, \quad h_{I}<0
\end{gathered}
$$

where $\hat{w}$ is the rate of growth of nominal wages, $v_{W}$ is the target wage share of workers, $v$ is (as previously defined) the actual wage share, $\hat{p}$ is the rate of price inflation, $v_{F}$ is the target wage share of firms, $I$ represents institutional features of the labour market that create employment and/or income insecurity amongst workers, and the parameters $\mu$ and $\phi$ denote the relative power of workers in the wage bargain and the relative power of firms in product markets, respectively. ${ }^{28}$ Equations (1) and (3) constitute a simplified form of the conflicting-claims model of inflation due originally to Rowthorn (1977). The simplifications arise from the omission of productivity growth and expectations as independent variables.

\footnotetext{
${ }^{28}$ Note that, for the sake of simplicity, $v_{W}$ is treated as being independent of $e$ and $I$ even as $\mu$ is modelled as being endogenous to these variables. See, however, Setterfield and Lovejoy (2006) for discussion of the endogeneity of workers' aspirations. Note also that, in what follows, we abstract entirely from changes in $\phi$, $v_{F}$ and $v_{W}$ in order to highlight the particular importance of changes in the values of $\mu$ for the structure and performance of US capitalism over the past thirty years. It is, however, quite possible that changes in $\phi, v_{F}$ and/or $v_{W}$ have contributed to the macroeconomic outcomes analyzed in this chapter.
} 
Hence note that in equation (1), for example (and ceteris paribus), workers would need to increase nominal wages at a rate equivalent to the growth of labour productivity simply in order to maintain the current value of the wage share (much less advance it towards the target value, $\left.v_{W}\right)$, given that $v=\frac{\omega}{q}=\frac{w / p}{q}$. This concern is eliminated if, for the sake of simplicity, we assume that $\hat{q}=0{ }^{29}$ It is also possible that workers reference an expected rate of inflation when seeking wage increases in accordance with equation (1) given that ceteris paribus, and once again recalling that $v=\frac{w / p}{q}$, they need to raise nominal wages in tandem with any increase in prices in order to maintain the current value of the wage share. Abstracting from concerns with expectations and productivity growth is worthwhile in the current context, however, because our objective here is to highlight the role of conflict in the determination of outcomes such as $v$ and $\hat{p}$ and, in particular, the changing influences on this conflict as a result of the transition of US capitalism towards neoliberalism.

The underlying theory in equations (1) and (2) is that workers and firms care about achieving 'fair shares' of total income (reflected in the targets $v_{W}$ and $v_{F}$ ), and strive to inflate nominal wages and prices (respectively) in the pursuit of these fair shares ${ }^{30}$ Hence $\hat{w}$ is increasing in $v_{W}$ and decreasing in $v$ in equation (1), while $\hat{p}$ is increasing in $v$ and decreasing in $v_{F}$ in equation (2). Equations (11) and (2) combine to yield equilibrium values for the rate of inflation $\left(\hat{p}^{*}\right)$ and the wage share $\left(v^{*}\right)$ under the equilibrium condition $\hat{w}=\hat{p}$, which is necessary to ensure a constant wage share $(\dot{v}=0)$ given that $v=\frac{w / p}{q}$ and $\hat{q}=0$ by hypothesis. These equilibria can be written as:

$$
\hat{p}^{*}=\frac{\mu^{*} \phi\left(v_{W}-v_{F}\right)}{\mu+\phi}
$$

\footnotetext{
${ }^{29}$ Note that this simplifying assumption also means that statements about the wage share are equivalent to statements about the value of the real wage and vice versa, since with $\hat{q}=0$ any variation in $\omega$ is reflected in equal proportional variation in $v$, and vice versa.

${ }^{30}$ The wage share pursued by firms, $v_{F}$, can be associated with a target value of the mark up $\left(\tau_{F}\right)$ in a simple mark-up pricing equation of the form $p=(1+\tau) w / q$, given that it follows from this equation that $\tau_{F}=\frac{1-v_{F}}{v_{F}}$.
} 


$$
v^{*}=\frac{\mu v_{W}+\phi v_{F}}{\mu+\phi}
$$

Note that in equation (5), the equilibrium wage share is a weighted average of the distributional targets $v_{W}$ and $v_{F}$ : as long as $\mu, \phi \neq 0$, neither workers nor capitalists are able to set $v$ equal to their preferred, target values. Instead, equilibrium price inflation $\hat{p}^{*}$ emerges as the residual outcome of the 'balance of conflicting forces' that keeps the functional distribution of income constant in equilibrium.

Equation (3) relates the bargaining power of workers directly to the employment rate $e=N / L$, where $N$ is the level of employment (as previously defined) and $L$ the size of the labour force, and indirectly to the degree of institutionalized worker insecurity, $I$. This equation captures a trade off between the rate of unemployment $(U=1-e)$ and the degree of institutionalized worker insecurity necessary to maintain a constant level of worker bargaining power, $\mu$. As will become clear below, this allows us to model the substitution of institutionalized worker insecurity for unemployment as a worker discipline device under neoliberal capitalism.

Referring to equations (3), (4) and (5), consider first the derivatives:

$$
\frac{d \hat{p}^{*}}{d e}=\frac{d \hat{p}^{*}}{d \mu} \frac{d \mu}{d e}=\frac{\phi^{2}\left(v_{W}-v_{F}\right)}{\left(\mu^{*}+\phi\right)^{2}} h_{e}>0
$$

and:

$$
\frac{d v^{*}}{d e}=\frac{d v^{*}}{d \mu} \frac{d \mu}{d e}=\frac{\phi\left(v_{W}-v_{F}\right)}{\left(\mu^{*}+\phi\right)^{2}} h_{e}>0
$$

These results establish the existence of 'standard' (price inflation) and wage-share Phillips curves, respectively: as the employment rate rises (unemployment rate falls) and the labour market tightens, the rate of inflation and the wage share of income both rise.

Now consider the derivatives: 


$$
\frac{d \hat{p}^{*}}{d e}=\frac{d \hat{p}^{*}}{d \mu} \frac{d \mu}{d I}=\frac{\phi^{2}\left(v_{W}-v_{F}\right)}{\left(\mu^{*}+\phi\right)^{2}} h_{I}<0
$$

and:

$$
\frac{d v^{*}}{d I}=\frac{d v^{*}}{d \mu} \frac{d \mu}{d I}=\frac{\phi\left(v_{W}-v_{F}\right)}{\left(\mu^{*}+\phi\right)^{2}} h_{I}<0
$$

These results demonstrate the capacity for variations in institutionalized worker insecurity to 'shift' the standard and wage-share Phillips curves, so that as $I$ rises, both the rate of inflation and the wage share of income fall at any given rate of employment (unemployment).

Finally, consider the total derivatives:

$$
d \hat{p}^{*}=\frac{\partial \hat{p}^{*}}{\partial e} d e+\frac{\partial \hat{p}^{*}}{\partial I} d I
$$

and:

$$
d v^{*}=\frac{\partial v^{*}}{\partial e} d e+\frac{\partial v^{*}}{\partial I} d I
$$

It is clear from inspection that because the partial derivatives in both (10) and (11) are of opposing signs (see equations (6)-(9)), we can find $d e, d I>0$ such that $d \hat{p}^{*}, d v^{*}=0$. This is the essence of the neoliberal supply side as described earlier, and its apparent restitution of Golden Age macroeconomic performance (seen in table 1) through the institution of an incomes policy based on fear $(d I>0)$. The result is illustrated in Figure 5 .

Suppose we begin at the equilibrium $v_{1}, \hat{p}_{1}$ in the north-east quadrant of Figure 5. This puts the economy at points $A$ and $A^{\prime}$ (respectively) on the wage-share and standard Phillips curves $W S P C_{1}$ and $S P C_{1}$ in the south-east and north-west quadrants of the figure. Ceteris paribus, a rise in institutionalized worker insecurity $I$ will lower worker bargaining power (to $\mu_{2}$ ) and so lower the equilibrium wage share and inflation rate (to $v_{2}$ and $\hat{p}_{2}$, respectively. But if accompanied by a simultaneous increase in $e$ (and hence decrease in $U$ from $U_{1}$ to $U_{2}$ ) 
Figure 5: Restoring Macroeconomic Performance with an Incomes Policy Based on Fear

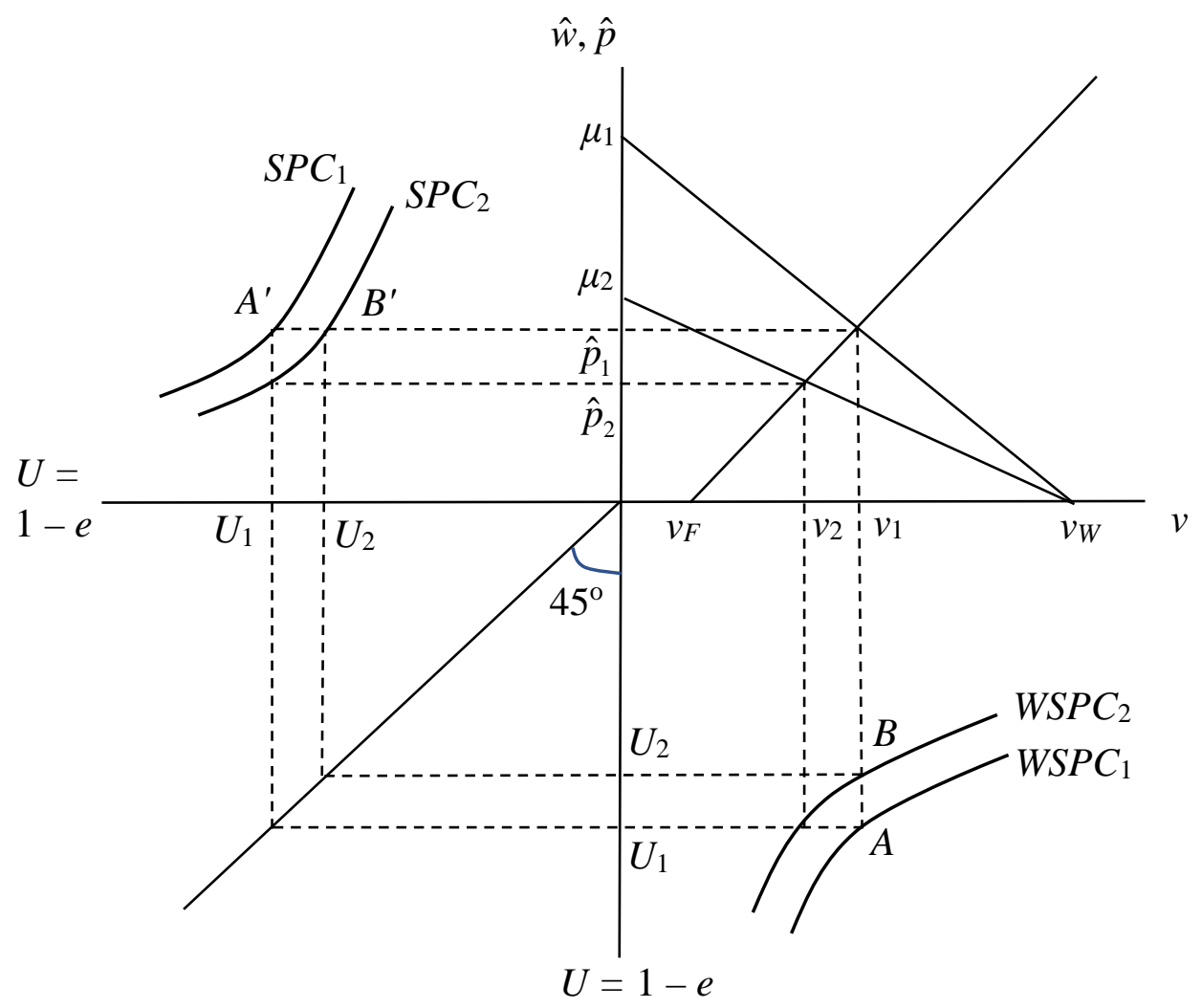


sufficient to exactly offset the impact of the change in $I$ on $\mu$, the equilibrium in the north-east quadrant of figure 5 will be restored to its initial configuration. This will bring the economy to rest at points $B$ and $B^{\prime}$ (respectively) on the new wage-share and standard Phillips curves $W S P C_{2}$ and $S P C_{2}$ in the south-east and north-west quadrants of the figure. In the final analysis, macroeconomic performance will have improved by conventional metrics, the economy realizing a lower rate of unemployment at $U_{2}$ without any accompanying 'sacrifice' in terms of a higher rate of inflation.

In addition to explaining the stylized facts of neoliberalism's restoration of Golden Age standards of macroeconomic performance during the 1990s, figure 5 also furnishes an explanation for the recent shift in the centre or focus of the Goodwin pattern, brought about by the change in the structure of distributional conflict due to the incomes policy based on fear. Hence as is evident from the bottom-right quadrant of figure 5, the transition to the Neoliberal Boom facilitated a longer-term rise in the rate of employment without any accompanying rise in the wage share. This same pattern is clearly evident in figure 2 where, over the course of events from 1982-2000, it is evident that the employment rate rose substantially (by fully 6 percentage points) even as the wage share remained roughly constant.

\subsection{The consolidation of neoliberalism and the breakdown of the Goodwin pattern}

So far, the transition to neoliberalism and the associated creation of institutionalized worker insecurity and an incomes policy based on fear have been used to explain a recent shift in the centre or focus of the Goodwin pattern, the like of which has been observed previously in the data. But what of the purported breakdown in the Goodwin pattern since 2000? First, events from 2000-2007 can be thought of as reflecting the completion of the neoliberal project - an extension of the events depicted in Figure 5, with the relatively modest increase 
in employment during the 2000-20007 interval now more than fully offset by further increases in institutionalized worker insecurity, resulting in a net decline in the wage share even in the course of a short-cycle boom. This accounts for the simultaneous improvement in real performance and accompanying fall in the wage share 2000-2007 remarked upon by Nikiforos (2017) and evident in figure 2. Note that what is being contemplated here is consistent with the notion, entertained briefly in section 3 , that the data in figure 2 may be explained by the interaction of countervailing structural (trend) and cyclical factors: a $d I>0$ (resulting from still-ongoing and longer-term structural changes together with a de $>0$ (as a result of a cyclical boom) such that $d v^{*}<0$. Indeed, an explanation of this sort could be extended to cover the entire post-2000 period, without appealing to the notion that the profit squeeze mechanism intrinsic to the Goodwin pattern has broken down at all. But alternatively, developments since the Great Recession might be explained by the workings of a 'complete' neoliberal project reflected in an 'institutionally entrenched' incomes policy based on fear, in which worker bargaining power has been brought so low that we effectively observe $\mu=0$ at any but the very highest rates of employment. The result of this regime is that tightening of the labour market has no effect on either inflation or the wage share, rendering both the standard and wage-share Phillips curves flat. To see this, suppose we-re-write equation (2) as:

$$
\hat{p}=\phi\left(v-v_{F}\right)+\varepsilon
$$

where $\varepsilon \sim\left(\bar{\varepsilon}, \sigma_{\varepsilon}^{2}\right)$ captures supply shocks associated primarily with commodity prices and $\bar{\varepsilon}>0$. Solving equations (1) and (12) for $v^{*}$ and $\hat{p}^{*}$ under the assumption that $\mu=0$, we now obtain the steady-state solutions:

$$
\hat{p}^{*}=\bar{\varepsilon}
$$




$$
v^{*}=v_{F}
$$

The workings of this modified conflicting-claims system are illustrated in Figure 6. Effectively, employment (unemployment) has been 'decoupled' from the dynamics of distributional conflict, so that developments in the north-east and south-west quadrants now function independently of another. This results in 'flat' Phillips curves in both the north-west and south-east quadrants, wherein variations in employment (unemployment) have no effect on inflation or the wage share (respectively), ceteris paribus. Both inflation and the wage share are now determined independently of the 'tightness' of the labour market, the rate of inflation depending only on the average rate of growth of commodity prices $\bar{\varepsilon}$, and the wage share depending only on the pricing decisions of firms (whose mark up pricing decisions are now the unilateral determinant of the real wage and hence, given $\hat{q}=0$, the wage share of income) It is as a result of this unilateralism in the determination of $v$ - the transformation of an enduring source of conflict into an effective 'no contest' by virtue of the institutional structure of neoliberalism - that we observe $v^{*}=v_{F}$ in Figure 6 .

Note, however, that the suppression of the income share - real activity nexus described above and accounted for by the notion of an 'incomes policy based on fear' does not delegitimize the emphasis on distributional conflict that is central to understanding the Goodwin pattern. On the contrary, it suggests that even when the Goodwin pattern is not evident in the data, explanation for its absence is to be found in the precise (historical) form and expression of distributional conflict itself. In other words, and much like Sherlock Holmes's 'dog that did not bark', ${ }^{32}$ distributional conflict remains a significant feature of capitalist

\footnotetext{
${ }^{31}$ Unlike the general form of the conflicting claims framework in which the value of the real wage $\omega=\frac{w}{p}$ is contested, the real wage is now determined - as in simple mark-up pricing theory - by the establishment of a price level $p=(1+\tau) \frac{w}{q}$ subsequent to the setting of the nominal wage, $w$, where $\tau=\tau_{F}=\frac{1-v_{F}}{v_{F}}$.

${ }^{32}$ In Sir Arthur Conan Doyle's Silver Blaze, Sherlock Holmes remarks that the fact that a dog did not bark during the night on which a race horse was removed from its stable provides evidence as to who was likely responsible for the horse's removal.
} 
Figure 6: The institutionally entrenched incomes policy based on fear

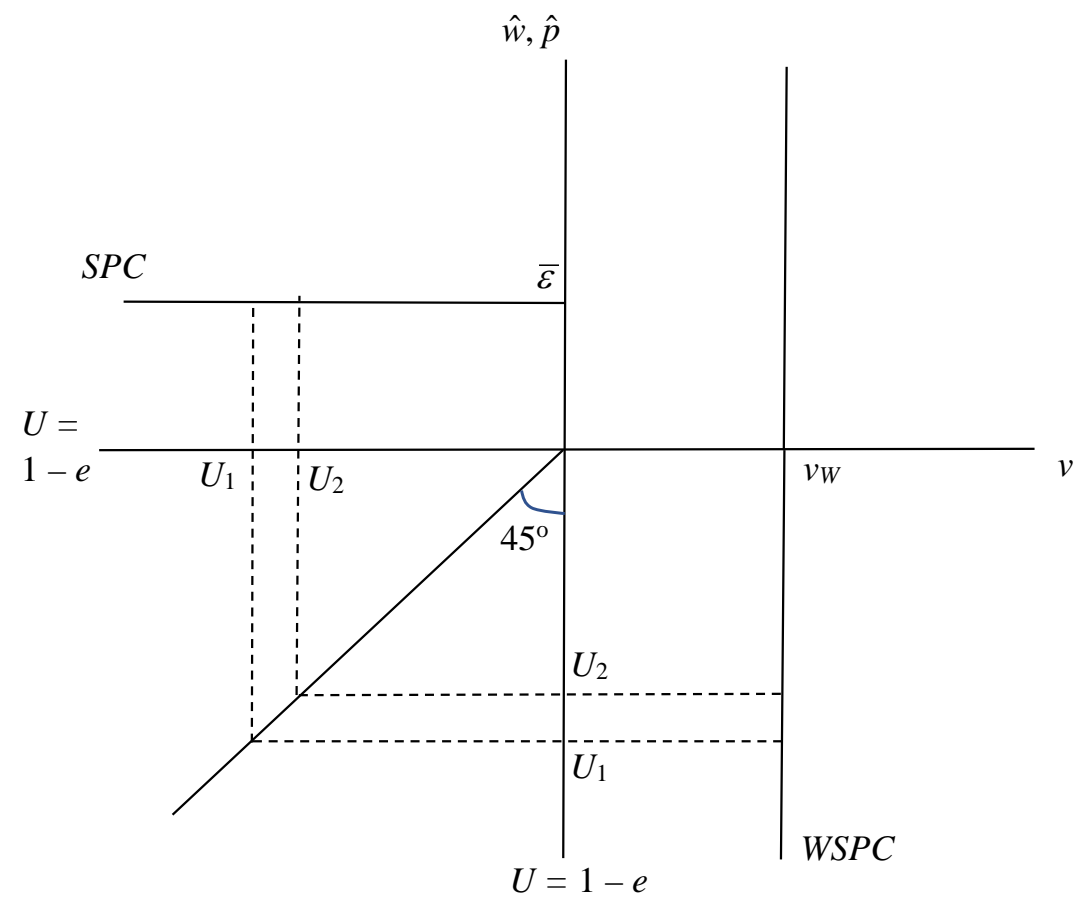


macrodynamics even when it is seemingly absent, by virtue of its not responding to changed economic circumstances and thereby not exerting pressure on measured income shares. Conflict therefore remains of central importance for the analysis of capitalist macrodynamics even during the neoliberal era, when the Goodwin pattern has not so much 'broken down' as been suppressed by institutional change that has altered the precise manifestation of conflict.

\subsection{An explanation more apparent than real?}

It might be argued that the revised model responsible for the steady-state outcomes in equations (13) and (14) cannot, in fact, provide a plausible explanation for recent macroeconomic outcomes consistent with the disappearance of profit squeeze dynamics and a breakdown in the Goodwin pattern. In the first instance, the model might be subject to the theoretical objection that it overlooks certain aspects of the operation of the labour market as $e$ rises to very high rates. Hence even if structural change in the labour market diminishes the bargaining power of labour, as the labour market tightens it may come to resemble an auction market in which excess demand for labour bids up wages (nominal and real) and hence the wage share. At this point, however, it is important to note that in Figure 6 (as in Figure 5 before it), and corresponding to the account of the onset of neoliberalism summarized in table 1, $U=1-e$ corresponds to a narrow or conventional measure of unemployment such as U3. The importance of this observation is that the structural change associated with the neoliberal incomes policy based on fear has rendered such conventional measures of labour market slack less meaningful. For example, it has introduced and/or increased forms of underemployment (such as involuntary part-time and temporary work) and has coincided with (if not caused) disguised and intensified unemployment in the form of the discouraged worker effect and the increasing duration of unemployment spells ${ }^{33}$ At the same time, it has given

\footnotetext{
${ }^{33}$ Recall that these phenomena are the focus of the broad measures of labour market slack, such as U6 and unemployment intensity, discussed in section 3.1 .
} 
rise to 'barge economics' and the credible threat of plant relocation, so that 'neoliberalism in one jurisdiction' (such as the US) operates as a centre-periphery model in which the centre imports unemployment (from the periphery) as a worker discipline device (Setterfield (2000), Peck (2002, p.212)). The power over political jurisdictions that accompanies the workings of this mechanism also allows corporations to influence the very workings of the domestic labour market. Hence in a 'textbook' auction market, excess demand is resolved by a rise in prices that changes the quantities demand and supplied. In some echelons of the US labour market, however, excess demand is now presented as evidence that 'Americans aren't willing to perform these jobs', and gives rise to political pressure for migratory inflows designed to increase labour supply and reconcile supply and demand at the (unchanged) price originally offered on the demand side. In this way, even as domestic unemployment falls over the course of a cyclical boom, the US labour market remains slack by virtue of its being embedded in a global reserve army of labour that mobile and politically-powerful productive capital can exploit.

The upshot of these considerations is that even if U3 falls to historically low levels, the US labour market does not truly tighten so as to induce auction-market-like conditions in which wages and the wage share are necessarily bid up by employers as a result of excess demand. This is evident in (for example) the trend increase in unemployment intensity remarked upon in section 3.1 - so that as seen in figure 4 (and despite its marked pro-cyclical behaviour) the level of $U_{\text {int }}$ at cyclical peaks is now higher than it was at the start of the millennium. This, in turn, draws attention to the fact that labour market slack and labour market structure are not as dichotomous as their treatment in figure 6 might make them appear. While real performance as conventionally measured has arguably become decoupled from distributional (and inflation) dynamics, the structural change with which the model depicted in figure 6 is associated has weakened the significance of measures such as U3 as indicators of labour market slack. This ensures that even as U3 falls to levels that suggest demand will bid up 
wages (and hence the wage share) in auction-market-like conditions, such conditions do not, in fact, materialize.

Second, the explanation for the recent disappearance of the Goodwin pattern furnished in section 3.1 focuses exclusively on recent changes in wage bargaining and their impact on real wage dynamics. But as previously noted, the behaviour of the wage share depends on both real wage and productivity dynamics, and according to various authors, productivity dynamics play a major role in explaining historical observation of the Goodwin pattern (Lavoie, 2017; Cauvel, 2018; Hartley, 2019). Is it possible, then, that focusing on real wage dynamics to explain the apparent breakdown of the Goodwin pattern is inappropriate?

Examination of the data suggests not, marked changes in real wage dynamics being a distinguishing feature of the neoliberal phase of growth. Table 2 presents the average annual rates of growth of real wages in the US economy over successive business cycle upswings since 1949. As can be seen, the average rates of growth of real wages during cyclical booms falls from 2.8\% during the Golden Age to 1.1\% during the 1975-1990 inter regnum, before rising again - in the manner one would expect following the onset of a new phase of growth - during the subsequent Neoliberal Boom. This increase is very modest, however, the rate of growth of real wages during the cyclical booms 1991-2001 and 2002-2007 averaging just 1.3\%. Moreover, and significantly for the purposes of this paper, the rate of growth of real wages falls during each of the three consecutive cyclical booms since the onset of neoliberalism. This is consistent with the notion that the rise, completion, and final entrenchment of an incomes policy based on fear affecting real wage and wage share dynamics in the US since 1990 has increasingly suppressed the sensitivity of real wages to any tightening of the US labour market in the course of short-term booms.

The data in table 2 do not demonstrate that real wage dynamics are exclusively responsible for determining high-frequency variation in the wage share in the US since 1990. But they are consistent with the claim that real wage dynamics have been affected by the advent 
Table 2: Average Annual Rates of Growth of the Real Wage in the US over Successive Cyclical Upswings, 1949-2019

\begin{tabular}{lc}
\hline & $\begin{array}{c}\text { Average Rate of Growth } \\
\text { of Real Wages }\end{array}$ \\
& \\
\hline \hline & \\
1949II - 1953II & 3.3 \\
1954III - 1957III & 3.6 \\
1958III - 1960II & 2.7 \\
1961II - 1969IV & 2.4 \\
1971I - 1973IV & 2.1 \\
1975II - 1980I & 1.2 \\
1983I - 1990II & 0.9 \\
1991II - 2001I & 1.6 \\
2002I - 2007IV & 1.0 \\
2009III - 2019IV & 0.8 \\
& \\
Golden Age (1949-73) & 2.8 \\
Inter Regnum (1975-90) & 1.1 \\
Neoliberal Boom (1991-2007) & 1.3 \\
& \\
\hline
\end{tabular}

Source: Author's calculations based on FRED data (fred.stlouisfed.org/series/PRS85006151) and NBER business cycle dating. 
of neoliberalism, and in a manner consistent with our explanation for the recent breakdown in the Goodwin pattern based on the final consolidation of an incomes policy based on fear. These observations are, in turn, supported by authors such as Hartley (2019), who shows that variance in real compensation explains more of the observed variance in the wage share during the neoliberal era than in previous periods, and by Mendieta-Muñoz et al. (2020), who show that US wage share dynamics have been dominated by real wage dynamics since 1985. They are also consistent with evidence that shows changes in nominal wage dynamics coincident with the advent of the neoliberal era, and associated with the loss of worker bargaining power (see, for example, Pacitti, 2020).

\section{Conclusions}

The Goodwin pattern can be considered an enduring empirical feature of high-frequency dynamics in advanced capitalism - so much so that when it is not evident in the raw data, an explanation for its seeming disappearance is required. Central to the hypothesis developed in this paper is the idea that neoliberal capitalism involves an 'incomes policy based on fear' Cornwall, 1990 - a "model of domination in which conflict is ameliorated essentially by means of coercion and in which the costs of ... [reducing] distributional conflict ... fall squarely on the shoulders of workers' (Setterfield, 2007, p.144). This has been achieved by a series of institutional changes, including deunionization, credible threats of outsourcing and plant relocation, and the threat of involuntary part-time and contingent work, that have institutionalized worker insecurity in the US economy over the past thirty years. This institutionalized worker insecurity has effectively replaced unemployment (as conventionally measured) as the key worker discipline device that moderates worker bargaining power, the resultant ability of workers to bargain for wage increases, and hence the behaviour of the wage share of income. The upshot of this mechanism is that the wage share has effectively become 
'decoupled' from labour market outcomes: it is no longer necessary to raise unemployment in order to discipline labour and reduce the wage share, while tightening the labour market no longer reduces labour market discipline and increases worker bargaining power sufficiently to directly affect the wage share.

This account of the modern dynamics of the US labour market is consistent with the apparent breakdown of the Goodwin pattern after 2000. It also suggests that the breakdown in the Goodwin pattern can be explained in terms of a transformation in the structure of class conflict during a particular phase of growth (neoliberalism) - conflict itself remaining central to our account of the patterns evident in the data. there is no doubt that these patterns are not, as yet, conclusive: the stylized facts are suggestive of a weakening of the profit squeeze mechanism without providing definitive proof of this weakening. Moreover, the theory developed to explain the breakdown of the Goodwin pattern may be a limit case towards which developments in contemporary capitalism are still tending, rather than an as-yet-fully-realized end state. As noted, the theory advanced in this paper can furnish an account of the apparent breakdown in the Goodwin pattern in which structural (trend) and cyclical factors interact and countervail, and in which the profit squeeze mechanism is still alive (if not altogether well).

But these qualifications aside, one important lesson that emerges unequivocally from the analysis advanced above is that distributional conflict is an enduring feature of capitalism. Whether conflict is explicit (as, for example, during the strike waves of the early 1970s) or suppressed by institutional arrangements that codify a specific (either more or less equitable) balance of power among conflicting claimants, it remains central to capitalist dynamics. Awareness of this fact, coupled with an ability to account for the precise manifestation of conflict, remain vitally important for explaining outcomes during any particular phase of capitalist growth. 


\section{References}

Araujo, R. A., M. J. Dávila-Fernández, and H. N. Moreira (2019). Some new insights on the empirics of Goodwin's growth-cycle model. Structural Change and Economic Dynamics 51, $42-54$.

Balogh, T. (1982). The Irrelevance of Conventional Economics. New York: W.W. Norton.

Barbosa-Filho, N. and L. Taylor (2006). Distributive and demand cycles in the US economy: a structuralist Goodwin model. Metroeconomica 57(3), 389-411.

Barrales-Ruiz, J., I. Mendieta-Muñoz, C. Rada, D. Tavani, and R. von Arnim (2020). The distributive cycle: Evidence and current debates. Working Paper 2020-07, Department of Economics, University of Utah.

Barrales-Ruiz, J. and R. von Arnim (2017). Longer-run distributive cycles: wavelet decompositions for the US, 1948-2011. Review of Keynesian Economics 5(2), 196-217.

Basu, D. and L. Gautham (2020). What is the impact of an exogenous shock to the wage share? VAR results for the US economy, 1973-2018. In D. Basu and D. Das (Eds.), Conflict, Demand and Economic Development: Essays in Honour of Amit Bhaduri, pp. 142-169. London: Routledge.

Baumol, W., S. Blackman, and E. Wolff (1989). Productivity and American Leadership: The Long View. Cambridge, MA: The MIT Press.

Blecker, R. and M. Setterfield (2019). Heterodox Macroeconomics: Models of Demand, Distribution and Growth. Cheltenham, UK: Edward Elgar.

Block, R. N., J. Beck, and D. H. Kruger (1996). Labor Law, Industrial Relations, and Employee Choice: The State of the Workplace in the 1990s. Kalamazoo, MI: W.E. Upjohn Institute for Employment Research.

Cauvel, M. (2018). Three essays on the empirical estimation of wage-led and profit-led demand regimes. Ph. D. thesis, American University, Washington DC.

Cornwall, J. (1990). The Theory of Economic Breakdown: An Institutional-Analytical Approach,. Oxford: Basil Blackwell.

Desai, M. (1984). An econometric model of the share of wages in national income: UK 1855-1965. In R. M. Goodwin, M. Krüger, and A. Vercelli (Eds.), Nonlinear Models of Fluctuating Growth, Berlin, pp. 253-277. Springer.

Flaschel, P. and G. Groh (1995). The classical growth cycle: Reformulation, simulation and some facts. Economic Notes 24, 293-326. 
Flaschel, P., H. Krämer, S. Luchtenberg, C. P. no, and M. Setterfield (2020). Capitalism, Inclusive Growth, and Social Protection: Inherent Contradiction or Achievable Vision? Cheltenham, UK: Edward Elgar.

Goodwin, R. (1967). A growth cycle. In C. Feinstein (Ed.), Socialism, Capitalism and Economic Growth, pp. 54-58. Cambridge: Cambridge University Press.

Harrison, B. and B. Bluestone (1988). The Great U-Turn: Corporate Restructuring and the Polarizing of America. New York: Basic Books.

Hartley, B. (2019). Accounting for endogeneity and secular trends in aggregative studies of growth and distribution, new school for social research, mimeo.

Harvie, D. (2000). Testing Goodwin: growth cycles in ten OECD countries. Cambridge Journal of Economics 24(3), 349-376.

Komlos, J. (2019). Trends and cycles in U.S. labor-market slack, 1994-2019. Applied Economics Quarterly (formerly: Konjunkturpolitik) 65(3), 209-235.

Lavoie, M. (2017). The origins and evolution of the debate on wage-led and profit-led regimes. European Journal of Economics and Economic Policies: Intervention 14(2), 200-221.

McAdam, P., S. Bridji, and M. Charpe (2019). Labor share and growth in the long run. Working Paper Series 2251, European Central Bank.

Mendieta-Muñoz, I., C. Rada, M. Santetti, and R. von Arnim (2020). The US labor share of income: what shocks matter? Review of Social Economy 0(0), 1-36.

Mendieta-Muñoz, I., C. Rada, and R. von Arnim (2020). The decline of the US labor share across sectors. Review of Income and Wealth.

Mohun, S. (2006). Distributive shares in the US economy, 1964-2001. Cambridge Journal of Economics 30(3), 347-370.

Mohun, S. and R. Veneziani (2008). Goodwin cycles and the US economy 1948-2004. In P. Flaschel and M. Landesmann (Eds.), Mathematical Economics and the Dynamics of Capitalism: Goodwin's Legacy Continued, pp. 107-130. London: Routledge.

Nikiforos, M. (2017). Uncertainty and contradiction: An essay on the business cycle. Review of Radical Political Economics 49(2), 247-264.

Osterman, P. (1999). Securing Prosperity: The American Labour Market: How It Has Changed and What to Do About It. Princeton, NJ: Princeton University Press.

Pacitti, A. (2020). The cost of job loss, long-term unemployment, and wage growth. Journal of Post Keynesian Economics, 1-28. 
Palley, T. I. (2019). The fracturing of globalization: Implications of economic resentments and geopolitical contradictions. Challenge 62(1), 49-66.

Paternesi Meloni, W. and A. Stirati (2020). Unemployment and income distribution: Some extensions of shaikh's analysis, institute for new economic thinking working paper no. 137. Technical report.

Peck, J. (2002). Labor, zapped/growth, restored? Three moments of neoliberal restructuring in the American labor market. Journal of Economic Geography 2(2), 179-220.

Perez-Arce, F. and M. J. Prados (2021). The decline in the US labor force participation rate: a literature review. Journal of Economic Surveys 35(2), 615-652.

Rowthorn, R. E. (1977). Conflict, inflation and money. Cambridge Journal of Economics 1(3), 215-39.

Setterfield, M. (2000). Is the new US social structure of accumulation replicable? Some remarks on the 'logic' of neoliberalism, mimeo. Department of Economics, Trinity College, Hartford, CT, USA.

Setterfield, M. (2005). Worker insecurity and u.s. macroeconomic performance during the 1990s. Review of Radical Political Economics 37(2), 155-177.

Setterfield, M. (2006). Balancing the macroeconomic books on the backs of workers: A simple analytical political economy model of contemporary U.S. capitalism. International Journal of Political Economy 35(3), 46-63.

Setterfield, M. (2007). The rise, decline and rise of incomes policies in the US during the postwar era: an institutional-analytical explanation of inflation and the functional distribution of income. Journal of Institutional Economics 3(02), 127-146.

Setterfield, M. and T. Lovejoy (2006). Aspirations, bargaining power, and macroeconomic performance. Journal of Post Keynesian Economics 29(1), 117-148.

Shaikh, A. (2016). Capitalism: Competition, Conflict, Crises. Oxford: Oxford University Press.

Skott, P. (1989). Conflict and Effective Demand in Economic Growth. Cambridge, UK: Cambridge University Press.

Skott, P. (2010). Growth, instability and cycles: Harrodian and Kaleckian models of accumulation and income distribution. In M. Setterfield (Ed.), Handbook of Alternative Theories of Economic Growth. Cheltenham: Edward Elgar.

Skott, P. (2017). Weaknesses of 'wage-led growth'. Review of Keynesian Economics 5(3), $336-359$. 
Skott, P. and B. Zipperer (2012). An empirical evaluation of three post-Keynesian models. European Journal of Economics and Economic Policies: Intervention 9(2), 277-307.

Stockhammer, E. and J. Michell (2016). Pseudo-Goodwin cycles in a Minsky model. Cambridge Journal of Economics 41(1), 105-125.

Zipperer, B. and P. Skott (2011). Cyclical patterns of employment, utilization, and profitability. Journal of Post Keynesian Economics 34 (1), 25-58. 